\title{
Cardiovascular adverse effects during itraconazole
}

\section{therapy}

\section{To the Editors:}

Itraconazole has been widely used in the treatment of fungal disease including chronic necrotising pulmonary aspergillosis (CNPA) [1, 2]. Its use has been associated with occasional reports of adverse cardiovascular events including congestive heart failure [3], hypertension (HT) [4], premature ventricular contractions [5] and even ventricular fibrillation [6]. However, these adverse effects have been considered to be uncommon, if not rare, occurrences. From September, 1992 to April, 2001, the US Food and Drug Administration received only 59 reports of potential cases of congestive heart failure with the administration of itraconazole [3]. Despite the recommendation that itraconazole should not be used for treatment of onychomycosis in patients with evidence of ventricular dysfunction and that monitoring of symptoms and signs of heart failure is required during itraconazole therapy, the association of itraconazole and heart failure is still considered to be controversial [7].

From January, 2005 to December, 2007, seven patients were diagnosed to have CNPA in our institution. Adverse cardiovascular events were found in three patients and suspected in one after the commencement of itraconazole therapy for a variable period of 3 weeks to 4 months. All patients were administered $400 \mathrm{mg}$ of itraconazole, daily. The first patient was a 58-yr-old male who developed congestive heart failure after receiving 3 weeks of itraconazole therapy. He had underlying diabetes mellitus (DM), HT and old tuberculosis (TB). He improved with diuretic therapy and itraconazole was withheld. The second patient was a 71-yr-old male with old TB, DM (with nephropathy, baseline creatinine of $\sim 400 \mu \mathrm{mol} \cdot \mathrm{L}^{-1}$ ) and HT who presented again 10 weeks later with congestive cardiac failure and acute on chronic renal failure. Itraconazole therapy was stopped. His condition improved with diuretic therapy with the serum creatinine level returning to baseline. The third patient was a 55-yr-old male with unremarkable past health and normal baseline blood pressure of $110 / 70 \mathrm{mmHg}$. His blood pressure elevated to $160 / 90 \mathrm{mmHg}$ after 3 months of itraconazole therapy. Other secondary causes of HT could not be identified. He was put on anti-HT therapy and itraconazole was continued. The last subject was a 60 -yr-old male who had underlying silicosis and old TB. His blood pressure after commencement of itraconazole was found to be elevated from baseline of $100 / 70 \mathrm{mmHg}$ to $120 / 80 \mathrm{mmHg}$. He was put on observation and itraconazole therapy was continued. He died at home 15 weeks after commencement of itraconazole, 2 days after the last medical follow-up.
Our experience alerted us that the adverse cardiovascular events associated with itraconazole were not an uncommon occurrence. At least three of our seven subjects developed either congestive heart failure or hypertension while receiving $400 \mathrm{mg}$ itraconazole, daily. The exact cause of the sudden death of the fourth patient was uncertain but we suspected major cardiac arrhythmia was the culprit. Patients with underlying risk factors, such as diabetes mellitus or hypertension, were probably more vulnerable to the cardiovascular adverse effects of itraconazole. We suggested that thorough cardiac assessment should be considered in all patients starting on itraconazole. Baseline echocardiogram might be indicated in patients with underlying diabetes mellitus or hypertension and close monitoring of blood pressure is mandatory during therapy.

\section{S-L. Fung, C-H. Chau and W-W. Yew}

Tuberculosis and Chest Unit, Grantham Hospital, Hong Kong, China.

\section{STATEMENT OF INTEREST}

None declared.

\section{REFERENCES}

1 Saraceno JL, Phelps DT, Ferro TJ, Futerfas R, Schwartz DB. Chronic necrotizing pulmonary aspergillosis: approach to management. Chest 1997; 112: 541-548.

2 Wong PC, Fung SL, Lee J, Wong CF, Chau CH, Yew WW. Chronic necrotizing pulmonary aspergillosis: a report of 9 cases with analysis of clinical picture, risk factors and treatment for outcome correlation. Monaldi Arch Chest Dis 2001; 56: 202-207.

3 Ahmad SR, Singer SJ, Leissa BG. Congestive heart failure associated with itraconazole. Lancet 2001; 357: 1766-1767.

4 Sharkey PK, Rinaldi MG, Dunn JF, Hardin TC, Fetchick RJ, Graybill JR. High dose itraconazole in the treatment of severe mycoses. Antimicrob Agents Chemother 1991; 35: 707-713.

5 Okamoto J, Fukunami M, Kioka H. Frequent premature ventricular contractions induced by itraconazole. Circ J 2007; 71: 1323-1325.

6 Nelson MR, Smith D, Erskine D, Gazzard BG. Ventricular fibrillation secondary to itraconazole induced hypokalaemia. J Infect 1993; 26: 348.

7 Slørdal L, Spigset O. Heart failure induced by non-cardiac drugs. Drug Saf 2006; 29: 567-586.

DOI: $10.1183 / 09031936.00021208$ 